\title{
Heart herniation after blunt chest trauma
}

\author{
Guglielmo Maria Actis Dato, MD, ${ }^{a}$ Anna Arslanian, MD, ${ }^{b}$ Pier Luigi Filosso, MD, Enrico Aidala, MD, ${ }^{a}$ \\ Mario Adduci, MD, ${ }^{\mathrm{C}}$ Gianluca Bardi, MD, ${ }^{\mathrm{a}}$ and Enrico Ruffini, MD, ${ }^{\mathrm{b}}$ Torino, Italy
}

$\mathrm{P}$ ericardial rupture after blunt chest trauma is a rare occurrence, ${ }^{1}$ in most cases associated with other major injuries. Pericardial rupture may result in cardiac herniation with kinking of the great vessels, hypovolemic shock, and a mortality as high as $50 \%$ depending on the associated visceral and parietal injuries.

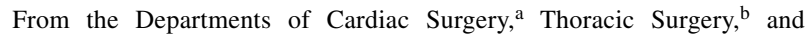
Emergency Surgery, ${ }^{\mathrm{c}}$ University of Torino, Torino, Italy.

Received for publication July 23, 2001; accepted for publication Aug 2, 2001. Address for reprints: Enrico Ruffini, MD, Thoracic Surgery, University of Torino, 3, Via Genova 10126, Torino, Italy (E-mail: enrico.ruffini@unito.it).

J Thorac Cardiovasc Surg 2002; 123:367-8

Copyright $@ 2002$ by The American Association for Thoracic Surgery

$0022-5223 / 2002 \$ 35.00+0 \quad \mathbf{1 2 / 5 4 / 1 1 9 8 7 9}$

doi:10.1067/mtc. 2002.119879
We present a case of heart herniation due to pericardial rupture after blunt chest trauma successfully managed with prompt surgical correction.

\section{Clinical Summary}

A 68-year-old man was involved in an automobile accident and was transferred to the nearest local hospital. A chest radiograph showed sternal and multiple rib fractures. Examination of the left hemithorax revealed an anterior flail chest. About 1 hour after admission the patient required orotracheal intubation for acute respiratory insufficiency; systolic blood pressure dropped to 60 $\mathrm{mm} \mathrm{Hg}$ and infusion therapy and inotropic support with dobutamine were started. Because of the progressive hemodynamic instability, the patient was transferred to our hospital, where a computed tomographic (CT) scan of the chest showed a left hydropneumothorax, pneumomediastinum, and heart dislocation into the left pleural space posteriorly, without evidence of laceration of the great vessels (Figure 1). 

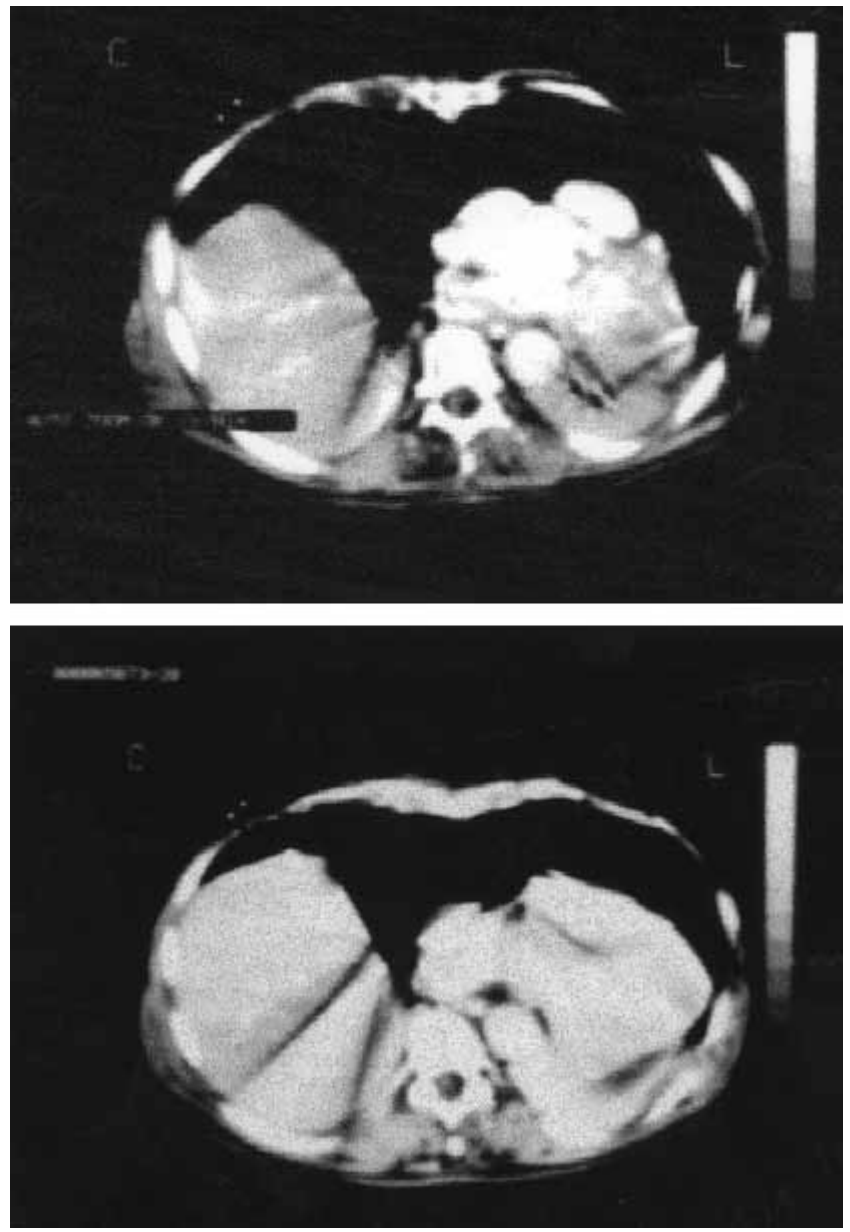

Figure 1. Chest CT scan showing dislocation of the heart into the left posterior region of the pleural space without radiologic evidence of rupture of the great vessels.

The patient was immediately moved to the operating room and an anterolateral left thoracotomy was undertaken. At inspection, a wide pericardial rupture $(6 \times 5 \mathrm{~cm})$ in the lateral portion of the pericardium along the phrenic nerve (which was intact) and total heart herniation were seen, with kinking of the great vessels. The heart was repositioned into the pericardial sac and partial coverage with pericardium was accomplished with loose nonabsorbable stitches to provide fixation of the heart without incarceration. The thoracotomy was closed as usual. The postoperative course was complicated by slow weaning from the ventilator requiring tracheostomy and acute renal insufficiency requiring hemodialysis. Sixty-five days after the operation, the patient was transferred to the rehabilitation service. He eventually was discharged to his home in excellent general condition.

\section{Discussion}

Pericardial rupture from blunt trauma is a rare but severe injury, very often associated with other major pulmonary and cardiac lesions. For this reason, the condition is frequently diagnosed at postmortem examination.

In case of isolated pericardial rupture, herniation of the heart through the pericardial defect results in progressive cardiac impairment because of kinking of the vessels with decreased venous return, hypotension, dyspnea, and jugular venous distention. Clinical manifestations include hypovolemic shock occurring immediately or in the first hours after the trauma.

Pericardial rupture can occur in either the diaphragmatic or the pleural portion of the pericardium. In autopsy series, pericardial rupture in the pleural portion has occurred more frequently on the left side, close to the phrenic nerve. ${ }^{2}$

Although a number of procedures have been proposed to diagnose traumatic pericardial rupture, including electrocardiography, echocardiography, pneumopericardium, ${ }^{3}$ and video-assisted thoracoscopy, ${ }^{4,5}$ very often, as in the present case, the clinical conditions of the patient are so compromised that surgical exploration should take priority over any other diagnostic measure besides chest CT scan, securing the airway, and providing an intravenous access.

Chest CT scan is the technique of choice to diagnose pericardial rupture and heart herniation: it can show the pericardial defect by the interposition of the lung between the great vessels and by the abrupt interruption of the pericardial layers.

Surgical treatment includes repositioning of the heart and correction of the pericardial defect. Some authors either leave the pericardium open or perform a completion pericardiotomy by enlarging the pericardial defect at the time of surgery, to reduce the risk of constrictive cardiogenic shock induced by edematous cardiac swelling after primary closure of the pericardial defect. In the present case, we preferred fixation of the heart after its repositioning in the pericardial sac by loosely closing the pericardium while leaving wide communication with the pleural space for drainage; great care was taken not to incarcerate the heart during pericardial closure.

In summary, traumatic cardiac herniation should be suspected in any patient in whom hemodynamic instability occurs rapidly after trauma without evidence of major bleeding. On most occasions there is no time for additional diagnostic measures other than chest CT scan. Prompt surgical exploration may yield excellent results.

\section{References}

1. Fulda G, Brathwaite CEM, Rodriguez A, Turney SZ, Dunham CM, Cowley RA. Blunt traumatic rupture of the heart and pericardium: a ten-year experience. J Trauma. 1991;31:167-73.

2. Clark DE, Wiles CS 3rd, Lim MK, Dunham CM, Rodriguez A. Traumatic rupture of the pericardium. Surgery. 1983;93:495-503.

3. Carrillo EH, Heniford TB, Dykes JR, McKenzie ED, Polk HC Jr, Richardson JD. Cardiac herniation producing tamponade: the critical role of early diagnosis. J Trauma. 1997;43:19-23.

4. Abo AJ, Vanttinen EA, Nelimarkka OI. Rupture of the pericardium with luxation of the heart after blunt trauma. J Trauma. 1987;27:560-3.

5. Thomas P, Saux P, Lonjon T, Viggiano M, Denis JP, Giudicelli R, et al. Diagnosis by video-assisted thoracoscopy of traumatic pericardial rupture with delayed luxation of the heart. J Trauma. 1995;38:967-70. 